Socioeconomic Institute

Sozialökonomisches Seminar

Working Paper No. 0206

\title{
How Special Interests Shape Policy \\ A Survey
}

Andreas Polk

July 2002 
Socioeconomic Institute

University of Zurich

Working Paper No. 0206

HOW SPECIAL INTERESTS SHAPE POLICY - A SURVEY

July 2002, $41 p$.

Author's address

Andreas Polk

Sozialökonomisches Seminar

Universität Zürich

Hottingerstrasse 10

$\mathrm{CH}-8032$ Zürich

Phone: +41-1-6343949

E-mail: atpolk@soi.unizh.ch

Publisher

Sozialökonomisches Institut

Bibliothek (Working Paper)

Rämistrasse 71

CH-8006 Zürich

Phone: +41-1-634 2137

Fax: +41-1-634 4982

URL: www.soi.unizh.ch

E-mail: soilib@soi.unizh.ch 


\title{
How \\ Special Interests Shape Policy
}

\section{A Survey}

\author{
Andreas Polk* \\ Socioeconomic Institute \\ University of Zurich
}

This version:

July 17, 2002

\begin{abstract}
This paper surveys recent approaches towards lobbying if interest groups influence the decision of an incumbent government. It describes the two main channels of influence which mainly exist in parallel, namely contribution payments and the transmission of information through lobbying. Recent extensions to the two basic lobbying models are discussed in great detail. Thereafter follows a short overview over current research, which tries to consolidate the two distinct branches of literature into a general lobbying model. The survey concludes with a summary of the main insights and indicates promising directions of further research.
\end{abstract}

JEL: D72, D78

Keywords: Lobbying, Interest Groups, Political Decision Making, Contribution Payments, Information Transmission

\footnotetext{
*Andreas Polk, Socioeconomic Institute, University of Zurich, Hottingerstrasse 10, 8032 Zurich, Switzerland, atpolk@soi.unizh.ch, www.soi.unizh.ch.

I am grateful to Armin Schmutzler, Matthias Gysler, Katrin Spitze and Christian Stoff for helpful comments.
} 


\section{Contents}

1 Introduction 1

2 Reduced Form Approaches $\quad 2$

3 Contribution payments to an incumbent government 3

3.1 Common agency theory . . . . . . . . . . . . 3

3.2 The basic lobbying model . . . . . . . . . . . 6

3.3 Extensions ........................ 10

3.3.1 Policy choice . . . . . . . . . . . . 10

3.3.2 Strategic interaction between governments . . . . . . . 11

3.3.3 Incentives of lobbies to cooperate . . . . . . . . . . 13

3.3.4 Group formation ............... 13

4 Signalling models $\quad 15$

4.1 The basic signalling model . . . . . . . . . . . . . . . . . 16

4.2 Lobbying competition and models of mass movement . . . . . . 22

4.3 Extensions . . . . . . . . . . . . . . . . . 25

4.3.1 Information acquisition . . . . . . . . . . . 25

4.3.2 Endogenous signalling costs: Access buying . . . . . . 26

4.3.3 Signalling as instrument with two purposes . . . . . . . . 27

4.3.4 Miscellaneous . . . . . . . . . . . . . . . . 27

$\begin{array}{lll}5 & \text { The instrument choice of lobbies } & 27\end{array}$

$\begin{array}{llr}6 & \text { Conclusions } & 29\end{array}$ 


\section{Introduction}

Almost all political decisions are influenced by special interests. Politicians pay tribute to interest groups' preferences, and interest groups spend remarkable resources to shape policies in their favor. A lot of theoretical research has been undertaken on these issues in the last years, which led to considerable new insights. The aim of this article is to lay down the most important approaches in this field.

This surveys considers the activities of a given set of lobbies, which try to influence the political decision of an incumbent politician. ${ }^{1}$ Research on these issues began with reduced form and rather abstract models of political influence, which provide some general insights and have found many applications. However, they treat the political process mainly as a black box. Newer approaches like the common agency framework or signalling models recently advanced much. They provide a microeconomic framework of lobbying, which nowadays represents the "state of the art". These models, as well as the most important extensions, are reviewed in great detail. The questions I wish to address in the following sections are:

What are the welfare effects of lobbying?

For instance, does lobbying increase or decrease welfare? Under what circumstances is lobbying welfare enhancing? And what is the type of improvement achieved through lobbying?

\section{Who benefits from lobbying?}

The question arises whether interest groups always benefit if they engage in lobbying. Or may it be the case that interest groups lobby without any effect? How does lobbying competition affect the distribution of benefits? Does the politician benefit from lobbying?

\section{What are relevant policy fields for lobbying?}

This question is closely related to the distribution of benefits. One would expect that interest groups try to influence those policy fields where lobbying may be successful. What are the characteristics of relevant policy fields?

A shortcoming of these approaches is that they mainly exist in parallel, which means that lobbying is either conceptualized as contribution payments or transmission of information. However, lobbying often consists of combined forms of these activities. It is not yet well understood which way of influence an interest group prefers, and what the relevant conditions for this choice are. The literature has started to answer these questions recently, which might yield to a consolidation of these yet two distinct branches of research into a general lobbying model. This survey will also take account of these promising first 
approaches.

My approach contrasts with existing surveys on lobbying in several respects. ${ }^{2}$ First, most of these surveys cover only a specific branch of the literature, i.e. either common agency or signalling models, but not both. There is a lack of surveys which cover all these approaches in a comprehensive way and relate them to each other. Second, as the literature recently advanced much, important extensions to the basic lobbying models need to be covered. To my best knowledge, approaches like the models of mass movement, the questions of instrument choice, models of group formation, or the choice of lobbying instruments have not yet been surveyed. My contribution tries to fill this gap and give a comprehensive overview over all relevant approaches. Third, many surveys focus on political economy models in the context of trade theory, as much of the pioneering research has been conducted in this field of research. In contrast, the objective of this survey is to give a broad and general intuition of how lobbying affects politics. It shall not be restricted to trade policy but cover all relevant topics of policy formation, as for instance the provision of public goods, regulation of industries, or environmental policy. Reference to trade is given only if it appears crucial for an understanding of the underlying effects.

\section{Reduced Form Approaches}

Reduced form lobbying models abstract from certain aspects of individual behavior. As these are already surveyed extensively, I will restrict myself to a broad overview (Helpman 1995, Rodrik 1995, Potters and van Winden 1996). The regulatory approach by Peltzman (1976) assumes that the politician sets a policy in order to maximize a weighted sum of special interests utility and aggregate welfare. These weights are exogenous. They can be thought of as resulting from an underlying lobbying process which is not explicitly analyzed. Hence, the regulatory approach focuses on the determination of the policy outcome, given that some kind of special interest activities lead to a policy bias in favor of a certain group. This approach has found many applications, mostly in the context of international trade policy (compare for instance Hillman (1982), Hillman (1989), Long van and Vousden (1991), Maggi and Rodriguez Clare (2000), Hahn (1990)).

The policy formation approach by Becker (1983) focuses on the lobbying process, but abstracts from individual behavior of the politician. Instead, it introduces an "influence function", which states how realized policies depend on lobbies' contribution payments. The approach determines the lobbying efforts endogenously and derives comparative statics results. For instance, lobbying 
increases if the deadweight loss of redistribution becomes more important or the politician caters more to special interests. Several applications of this model exist, again predominantly in the context of international trade policy (compare for instance Findlay and Wellisz (1982), Wellisz and Wilson (1986), Pecorino (1997), Damania (1999), Polk and Schmutzler (2002)).

\section{Contribution payments to an incumbent gov- ernment}

This section focusses on the incentive motive of lobbying. Contributions provide incentives for the politician to deviate from a first best policy choice. In contrast to the reduced form models of section 2 , these models fully specify the objective function of both the politician and the interest groups. This allows for an analysis of strategic interaction amid interest groups, and vis a vis the politician. Moreover, lobbies' objective functions result from a fully specified microeconomic general equilibrium model, and are not made ad hoc. This allows further insights concerning the resulting equilibrium policies.

The models of this section make use of theoretical results from common agency theory, which comprises situations in which a set of principals influences the decision of a common agent (Bernheim and Whinston 1986a, Bernheim and Whinston 1986b). This general setup, which is not specific to lobbying games, will be described in section 3.1. Specific applications to lobbying are crucial for an understanding of how special interest influence works. I will discuss an application to international trade theory extensively in section 3.2, which nowadays serves as a workhorse model (Grossman and Helpman 1994). I focus on the underlying intuition which is valid for a broad class of lobbying applications and not restricted to trade theory (compare for instance Aidt (1998) in the context of environmental policy, and Neven and Röller (2000) in the context of regulation theory). Recent approaches to lobbying, which are mainly extensions of the basic model, will subsequently be discussed in section 3.3 .

\subsection{Common agency theory}

The common agency framework is characterized by an agent and a set of principals (Bernheim and Whinston 1986a). The agent chooses an action $p$ among a feasible set of actions, which affects his own utility, $W(p)$, and that of the principals $i=1 \ldots n$. As the individual utility levels $U_{i}(p)$ of all principals depend on the action of the agent, principals face an incentive to influence 
his choice. In the first stage of the game, each principal makes a contingent contribution offer. These offers are individual payment functions $C_{i}(p)$, which state money rewards to the agent for each possible action he might choose. Individual payment functions thus map actions into money payments. The agent observes the contribution offers and decides which action to choose in the second stage of the game. Then principals make their payments which, in conjunction with the chosen action, determine the individual utility levels of all players.

Lobbying applications fit well into this framework: The politician (the agent) decides about a policy $p$ which affects the payoffs to the principals (the interest groups), who in turn try to influence his choice. In the first stage of the game, each lobby decides on a non-negative contribution function $C_{i}(p)$, which is a menu offer to the politician, stating how much money will be paid for each alternative policy realization. In the second stage, the politician observes these offers, determines the policy, and collects the respective money offers. The politician may well have preferences about the policy. For instance, a benevolent politician will prefer the policy which maximizes aggregate welfare. Any deviation then reduces aggregate welfare, and thereby his utility level. Contribution offers by special interest groups serve to compensate the agent for any deviation from the welfare maximizing policy, which gives them the flavor of political bribes. On the other hand, if the politician is completely opportunistic, he cares only about contributions, but not about the policy itself.

A political equilibrium consists of a policy choice $p^{*}$ and a set of individual contribution schedules $\left\{C_{i}^{*}(p)\right\}_{i}$. The equilibrium $\left[\left\{C_{i}^{*}(p)\right\}_{i}, p^{*}\right]$ determines the utility levels of the lobbies, $U_{i}\left(p^{*}\right)-C_{i}^{*}\left(p^{*}\right)$, and the utility of the agent, $W\left(p^{*}\right)+C^{*}\left(p^{*}\right)$, with $C^{*}\left(p^{*}\right) \equiv \sum_{i} C_{i}^{*}\left(p^{*}\right)$, such that

- The politician maximizes his payoff through the choice of $p^{*}$, given the set of equilibrium contribution functions $C_{i}^{*}(p)$, i.e.

$p^{*} \equiv \arg \max W(p)+C^{*}(p)$.

- Each lobby maximizes its utility level through the choice of a contribution function $C_{i}^{*}(p)$, given the set of contribution functions of the other lobbies, $C_{-i}^{*}(p)$, and the resulting policy vector $p^{*}$.

The setup assumes that individual utility levels are separable in money income and the policy effect, and that any contribution offer is reliable in the sense that contribution payments are indeed made after the policy choice. Moreover, it is crucial that lobbies are fully informed about the payoff functions of all players: The equilibrium demands that each lobby is able to calculate how policies affect 
the other lobbies and the politician. In contrast, the politician only needs to observe the contribution offers of the lobbies. Hence the equilibrium exists if the politician is imperfectly informed about lobbies preferences. Finally, note that the common agency framework is characterized by non-cooperative behavior of all players. The approach is very general. It does not rely on specific assumptions concerning lobbying competition. For instance, if the interest groups follow a common interest, the resulting payoff-structure reflects free-riding incentives of lobbies. In this case, each group tries to contribute as few as possible for a certain policy deviation. In contrast, if lobbies follow opposing interests, the equilibrium focuses on the effect of severe lobbying competition.

Properties of the equilibrium: Bernheim and Whinston characterize any possible subgame perfect Nash-Equilibrium $\left[p^{*},\left\{C_{i}^{*}(p)\right\}_{i}\right]$ for the class of common agency games: Apart from some feasibility constraints, the equilibrium policy choice $p^{*}$ maximizes the utility level of the politician, given the set of optimal contribution functions $C_{i}^{*}(p)$. (This shouldn't surprise you much). Second, there is no lobby with a policy alternative $p^{o}$ which increases its payoff to such an extent that it is able to compensate the politician for a deviation towards $p^{o}$. If this were the case, the lobby would be able to modify its contribution schedule and induce the politician to choose $p^{o}$ instead. As a result, both would be better off and $\left[p^{*},\left\{C_{i}^{*}(p)\right\}_{i}\right]$ cannot be an equilibrium. The condition can also be interpreted in an alternative way: The optimal policy maximizes the joint payoffs to the politician and any one lobby, given the contribution payments of all other lobbies. If this were not the case, then the lobby and the politician could jointly increase their payoffs by a policy deviation and an appropriate compensation. $^{3}$ The third property is a condition on the contribution function of each lobby, which states that each lobby offers zero contributions for at least one policy choice. Suppose this condition did not hold for any lobby. Then this lobby could slightly reduce all its contribution offers by the same amount, without affecting the behavior of the politician: The politician compares all possible policy outcomes and the associated contribution payments. This optimization problem is not affected if a lobby reduces all contribution offers uniformly. Thus a lobby is able to increase its payoff without affecting the policy choice, if not at least one contribution offer is zero. This cannot be an equilibrium.

Truthful strategies and existence: Many equilibrium sets of policy choices and contribution functions may exist. The question thus arises if some of these are focal. This leads to the introduction of a refinement to the Nash-equilibrium, i.e. the notion of "truthfulness": A principal's strategy is truthful relative to some reference policy $p^{\prime}$ if his contribution function reflects his true willingness to pay for a deviation from $p^{\prime}$ to any policy alternative $p$. Thus, a 
truthful contribution schedule consists of offers which make a lobby indifferent between the reference policy and any policy alternative $p$ for which it offers positive contributions. ${ }^{4}$ A truthful Nash equilibrium is characterized by truthful strategies of all principals, and the reference policy is the equilibrium policy $p^{*}$.

The authors further show that the set of best response correspondences of any principal contains a truthful strategy. This implies that all individuals can do best and reveal their true willingness to pay for any possible policy alternative, given the opponents' anticipated contribution offers $C_{-i}(p)$, and the implied policy choice by the politician. Hence truthful Nash equilibria may be interpreted as being focal. However, they are not necessarily unique.

Moreover, any truthful Nash equilibrium implies an efficient policy choice, and each efficient policy choice can be supported by a truthful Nash equilibrium. That is, the policy outcome of the lobbying game is the same as the policy choice of a benevolent politician! To understand this, note that efficiency refers to the policy choice and the resulting payoffs of all principals and the agent, but not necessarily to efficiency measures related to aggregate welfare. For instance, if free trade is the first best policy and all relevant groups are organized, lobbying competition leads to a free trade; If only some organize, lobbying competition induces inefficiencies and leads to a deviation from free trade, although the political equilibrium is efficient from the politician's and the organized lobbies' point of view. The intuition for this result is as follows: All lobbies consider only their private benefits and costs through a policy deviation, but ignore its social effects. The politician internalizes these effects, as all lobbies reveal their true assessment of each policy alternative. If all groups organize, this leads to an efficient policy choice. This result is also important in order to determine whether an equilibrium is unique: If the common agency model is applied to a policy setup which has a unique first best policy, this policy is also realized in the lobbying game as a unique truthful Nash equilibrium.

\subsection{The basic lobbying model}

The first application of the common agency framework to a lobbying game is Grossman and Helpman (1994). ${ }^{5}$ The authors determine the structure of protection in a small open economy, where import competing and exporting sectors organize as lobbies. I will start with a sketch of the model and discuss extensions thereafter. These also refer to the context of international trade. The rest of this section will therefore be biased towards trade theory, as other policy applications are still rare. 
Assume a small open economy which takes world market prices as given. The economy consists of an exogenous set of sectors. Each sector produces a homogenous product with labor and a sector specific input. A good is considered importable if imports and domestic production satisfy domestic demand for that good, and domestic producers compete with foreign firms. A good is called exportable if the domestic sector exports the good and competes with foreign firms in the foreign market. Individuals have identical indirect utility functions which are separable in income and consumer surplus from consumption. Each individual owns specific factors of one sector. Factor specific income increases in the domestic price level of that particular good. Income consists of factor income, wage income, and tariff revenue.

Individuals differ only with respect to their sector specific income. They are grouped along sectoral lines, where each group or sector consists of a fraction $\alpha_{i}$ of individuals, with $\sum_{i} \alpha_{i}=1$. The model abstracts from incentives to organize as lobbies, and assumes an exogenously given set of lobbies, such that $\alpha_{L}$ is the fraction of all organized individuals (compare section 3.3). Each lobby faces a trade-off concerning the structure of protection, which determines domestic prices: The factor income of a group depends positively on the output price of that specific sector; moreover tariff revenue increases in the prices of all sectors, and decreases in the size of the export subsidies. These two aspects work towards higher protection. But the members of a lobby act as consumers as well, and consumer surplus decreases in output prices. This effect tends towards lower protection.

The politician determines domestic prices through the choice of the tariff structure. The timing of the game is familiar from the common agency setup: In the first stage of the game, each lobby determines its contribution schedule noncooperatively, which maps every possible domestic price structure into a contribution offer. In the second stage of the game, the politician observes these offers and decides on the structure of protection. He maximizes a weighted sum of aggregate welfare and contribution payments. The relative weight put on aggregate welfare is denoted by $\alpha$.

Besides the general results of the former section, which characterize the equilibrium, the following main insights are worth mentioning: First, the model gives a microeconomic foundation for the reduced form regulatory approach, which departs from the assumption that the government determines the tariff structure in order to maximize a weighted sum of aggregate welfare and contribution payments. The common agency theory tells us to focus on truthful contribution schedules, which reflect the effect of a marginal policy change on the payoff to that particular group. Hence if the politician maximizes a weighted sum of aggregate welfare and truthful contribution schedules in the common agency approach, he in fact maximizes a weighted sum of aggregate 
welfare and special interest utility. This is exactly what the reduced form regulatory approach assumes.

Second, the political equilibrium determines the tariff in an import competing sector i as

$$
\frac{t_{i}^{*}}{1+t_{i}^{*}}=\frac{I_{i}-\alpha_{L}}{\alpha+a_{L}} \frac{z_{i}^{*}}{\varepsilon_{i}^{*}}
$$

where $t_{i}$ is the tariff or subsidy in that sector, $I_{i}$ is a dummy variable which equals one if the sector is organized (and zero otherwise), $z_{i}^{*}$ is the equilibrium ratio of domestic outputs to imports, and $\varepsilon_{i}^{*}$ is the (positively defined) import demand elasticity in the sector. The equilibrium tariff is positive if the group is organized as a lobby, and negative otherwise, i.e. organized import competing sectors receive positive protection through import tariffs; unorganized import competing sectors receive negative protection through import subsidies. ${ }^{6}$ Intuitively, lobbies care for income and consumption. The income interest dominates with respect to the own sector: A high output price increases factor incomes, which outweighs the loss in consumer surplus of that good. The consumption effect dominates in all other sectors, as a lobby receives no factor income there and the gain from tariff revenue is too small. As a result, each lobby prefers consumption subsidies in all other sectors except its own, where it prefers a tariff. This is where conflict of interest between lobbies comes into play: From a lobby's perspective, some of the other sectors are also organized and lobby for high prices of their good and low prices in all other sectors. Thus lobbying efforts partly offsets each other. In sum, all organized sectors obtain positive protection. Sectors which are not organized do not influence the politician. They receive negative protection.

The resulting equilibrium tariff of an organized sector increases in the share of domestic production, because large sectors gain much from a marginal increase in protection and have an incentive to lobby intensively. But high protection also entails a two-fold cost: First, the social cost of protection is high in sectors with large import demand elasticities. The equilibrium tariff structure entails some Ramsey-like elements. Sectors facing inelastic import demand receive more protection, because the welfare loss through protection is relatively small. Moreover, this aspect becomes unimportant if the politician does not care much about aggregate welfare, and protection increases. Second, high protection also implies a cost for the organized interest groups in their role as consumers. If the fraction of organized individuals is large, consumer interests become more important and protection declines in organized sectors. In unorganized sectors, negative protection increases as the consumption interests of organized lobbies become more important. Note that even if the politician has no concern for aggregate welfare at all, the level of protection is limited due to the fact that lobbies partially internalize the cost of protection. 
How does conflict of interest affect the equilibrium policy? Suppose only one sector is organized as a lobby. The equilibrium policy is a tariff in the organized sector, and negative protection in all others. The lobby increases its income through high protection in its own, and consumption rents through negative protection in all other sectors. This is politically feasible, because there are no opposing forces if only one lobby exists. It also implies that if the size of the organized lobby is negligibly small $\left(\alpha_{L}=0\right)$, lobbies' consumption interests become unimportant, and the political equilibrium entails positive protection in the organized sector and free trade in all others. Moreover, the lobby receives the full surplus of its influence: Each lobby pays contributions which exactly compensate the politician for the policy he would have chosen if that lobby was not active. If only one lobby exists, this reference policy is the free trade equilibrium. The lobby compensates the politician for the protectionist policy deviation, and the politician receives a payoff which is equivalent to his free trade payoff. The lobby gets all the extra rent through the political interaction.

Note that the general common agency framework predicts that lobbying competition yields an efficient policy choice. Efficiency refers to the set of principals and the agent, notably the politician and all existing lobbies. If only a fraction of sectors organize as lobbies, the politically efficient outcome is not equivalent to the efficient welfare maximizing policy, which is free trade. The reason is that the politician and the lobby can increase their joint payoff by a deviation from free trade. This deviation imposes costs on all other individuals, which is only fully internalized if all individuals organize as lobbies. If this is not the case, inefficient outcomes occur.

Suppose next that all sectors organize as interest groups. Each group tries to increase protection in its own sector and reduce protection in all others. Special interests are fully opposed in this case. Free trade emerges in the political equilibrium. Intuitively, each lobby ignores social costs and tries to induce high protection in its own, and low protection in all other sectors. Truthful contribution offers reflect these incentives. The politician is thus able to internalize all effects through policy deviations. He implements the free trade outcome if all groups participate in the political contest. Moreover, he captures a rent through the political context. The politician will implement the same policy as without lobbying, and receives contribution payments in equilibrium. The reason is that each lobby must engage in lobbying to prevent an individually disadvantageous outcome. If a lobby does not participate, lobbying by its competitors implies negative protection in its own and positive protection in all other sectors. Lobbying engagement is thus necessary to prevent this unfavorable outcome, and the best possible policy from a lobby's point of view is free trade. Hence lobbies are trapped in a prisoner's dilemma. I now discuss if there is scope for lobbying cooperation in this case. 
Andreas Polk

\subsection{Extensions}

\subsubsection{Policy choice}

The basic lobbying model makes some particular assumptions which will be suspended in the following. Consider first the question of policy instrument choice. The basic lobbying model abstracts from this question, because there is only one instrument available. But it leaves room for conjectures. Suppose an efficient and an inefficient policy instrument are available. The conjecture is that the amount of lobbying competition determines the instrument choice: Suppose that a single group is organized and no lobbying competition prevails. In equilibrium, the lobby receives all of the surplus resulting from the political game. It compensates the politician for the cost of providing the service, which is lower if the efficient instrument is employed. Hence a lobby facing low competition prefers a more efficient instrument, because this decreases contribution payments to the politician. Next, suppose that all groups are organized and compete with each other. The contribution payment of each lobby is a compensation for not deviating from free trade. The deviation (and hence compensation) is smaller if the policy instrument is inefficient, because the costs of providing services is higher for the politician. Hence compensations are smaller with inefficient instruments. Consequently, lobbies prefer inefficient policy instruments when competition is severe. In other words: If competition among lobbies is weak, the ability to lobby is a benefit, and more efficient instruments decrease compensation payments. In contrast, if competition among lobbies is severe, the ability to lobby is a necessary duty in order not to remain unheard in the political process. In this case, lobbies prefer inefficient means, because this reduces obligatory compensation payments.

Several authors extend the basic lobbying game to the choice between various policy instruments, but do not explicitly discuss the relationship between the degree of competition and policy efficiency. For instance, Rama and Tabellini (1998) analyze two interest groups which compete with respect to one policy variable and coincide with respect to the other. The economy consists of two sectors. The unorganized sector produces only with labor. The import competing organized sector produces with labor and capital. Factor owners of the latter sector organize along factor lines, i.e. a lobby of workers and a lobby of capitalists exist. The available policies are a price increasing tariff, which benefits the workers and the capitalist alike, and a minimum wage in the import competing sector, which increases the payoff to the workers at the expense of capital owners. The authors show that a tariff redistributes income towards capitalists, and leads to allocative inefficiencies: The organized sector expands if protection is high, which attracts labor from the unorganized sector. The minimum wage works against the allocative inefficiency. Labor 
becomes more expensive, which tends to offset the initial incentive to expand production. The minimum wage corrects for the allocative inefficiency, given that a tariff exists. Hence labor politics redistribute income between capitalists and organized workers, and imply a second best outcome. Moreover, these policy instruments are strategic complements: The politician has an incentive to increase the minimum wage if the tariff is high, because it corrects for allocative inefficiencies.

Other contributions are Dixit (1996), who incorporates production and consumption subsidies/taxes and heterogenous group sizes into the basic model. This leads to consumption subsidies (taxes) of goods which are consumed above (below) average by organized lobbies. Maggi and Rodriguez Clare (2000) analyze the choice between voluntary export restraints, import taxes and import quotas in a trade model, and derive conditions for the use of each instrument. Resulting policies depend on the relative political weights of foreign lobbies to domestic importers, and on the shadow costs of taxation.

\subsubsection{Strategic interaction between governments}

The basic lobbying model assumes a small country. This implies that the agent sets the policy independently of possible countervailing measures by a foreign country, i.e. strategic interaction between different agents plays no role. Grossman and Helpman (1995) extent the basic lobbying model regarding this aspect and consider strategic interaction between two governments. This extension is relevant to the common agency model more generally: The governments now constitute two agents, which face influence from distinct sets of principals (the lobbies) in their home countries. Countries trade with each other, which establishes the link between domestic tariff structures. As a consequence, governments can no longer independently respond to lobbying activities, but need to take strategic interactions with the other government into account.

There are two countries, which have the same characteristics as in section 3.2. Countries trade exclusively with each other, which means that import demand and export supply as well as the endogenous tariff structures determine world market prices. The tariff structure in each country is a result of the political interaction between domestic lobbies and the government, and of the strategic interaction between both governments. The timing of the game corresponds to that of the basic lobbying game. The model assumes that lobbies influence only their domestic governments, but not the government of the foreign country.

Consider the case in which governments set trade policies non-cooperatively. Each lobby's payoff now depends on the trade policies of both countries, and 
not only on the domestic country. Accordingly, a contribution schedule maps each domestic tariff structure into money offers for any given trade structure of the foreign country. An equilibrium of this modified game is defined by a set of truthful contribution schedules of lobbies in each country and the resulting structures of protection in each country, such that the contribution offers and the resulting trade policies are mutual best responses. ${ }^{7}$

The resulting structure of protection reflects two elements. The first is the political aspect, which is the same as in the basic lobbying model: Due to political pressures, organized sectors tend to gain protection at the expense of unorganized sectors. Protection in a sector is high if the politician cares much for money, the group is small, and the sector is large. The second aspect is that protection also depends on strategic considerations by the governments. The outcome is an additional tariff component, which modifies the tariff structure through a terms of trade component. This terms of trade effect, which increases domestic tariff revenue, is familiar from the early strategic trade literature (Johnson 1954): It implies an export tariff for exporting sectors, and an import tariff for importing industries, which decreases in the import demand or export supply elasticities of the foreign country. Intuitively, high foreign elasticities imply strong foreign quantity reactions to domestic trade measures, which increases the deadweight loss of protection. ${ }^{8}$

The political element and the terms of trade effect may reinforce or dampen each other. Consider for instance an organized importing industry. Political pressures work towards an import tariff. So does the terms of trade effect, and both reinforce each other. Next consider an organized exporting industry. The political element works towards an export subsidy, but the terms of trade motive favors an export tax. In this case, the effects work against each other. The resulting trade structure depends on the relative strength of both effects.

How do political parameters affect protection? Consider for instance the case in which the domestic government becomes less benevolent, and contributions become more important. This implies that lobbying costs decrease and protection increases (compare section 3.2). But a change in the domestic trade structure now also affects the foreign country, because lobbies offer contributions in anticipation of the resulting tariff structures. Organized foreign exporters face an incentive to offset increased domestic protection through an increase in export subsidies, or a decrease in export taxes. Hence, the strategic interaction of both governments works against the initial effect of increased protection, and trade enhancement by the exporting country tends to offset the initial increase of trade protection by the importing country. As a result, increased domestic government sensitivity to special interests then benefits organized lobbies of that country. Moreover, the terms of trade and domestic welfare of this country increase. This is a surprising result: A government 
which gets more aligned to special interests tends to increase domestic welfare through the implied strategic reaction of the foreign country. However, this result depends crucially on the assumption that the foreign government does not change its own responsiveness to special interests in response.

\subsubsection{Incentives of lobbies to cooperate}

The common agency framework and the basic lobbying model indicate that lobbies face incentives to cooperate. Lobbying leads to excessive contributions if interest groups compete with each other. For instance if all sectors organize as interest groups in the basic lobbying model, each lobby pays contributions but the equilibrium policy remains free trade. This is the same outcome as if no contributions where paid at all, and scope for cooperation exists. In contrast, suppose that lobbies do not compete at all, which is the case if the consumption share of each lobby is negligibly small. Then, the joint payoff to all lobbies is the sum of the individual payoffs in the non-cooperative game setting. Hence no scope for cooperation among lobbies exists.

Rama and Tabellini (1998) analyze the incentives of labor and capitalist lobbies to cooperate (compare also Levy (1999) and Aidt (1997) for cooperation in the context of trade theory). Tariffs and minimum wages make up the available policy instruments (compare the preceding paragraphs about the topic of instrument choice). The authors derive conditions such that cooperative lobbying leads to higher payoffs than non-cooperative lobbying. Particularly, this tends to be the case if the sum of the joint payoffs between the government and any of the lobbies is high compared to the payoff to a coalition consisting of all lobbies and the government. Intuitively, if the government achieves a high joint payoff with any of the two lobbies alone, it is able to outplay the lobbies against each other and benefit from firm conflict of interest between lobbies. In contrast, if the joint payoff to a coalition of all players, that is the government and both lobbies, is high, there is an interest to include all relevant groups in the political process, even if lobbies behave non-cooperatively. This is the case of low lobbying competition, where gains from cooperation are small (compare Laussel and Le Breton (2001) for a generalization of this aspect in the context of common agency theory).

\subsubsection{Group formation}

Lobby groups are not single entities, but rather consist of individuals who contribute to the group's activities. This is of importance, because the benefit of lobbying has the characteristic of a public good if the induced policy change through lobbying affects all individuals in society and it is not possible to 
exclude anybody from it. Hence incentives to free-ride within lobbies may result, and the question arises under which conditions interest groups emerge. Although this question has been raised and discussed in the early beginning of public choice theory, this field of research has long been left aside, but recently faces greater interest again.

Olson (1965) asks which groups are more likely to overcome the free-rider problem and thus may be able to form a lobby. He focuses on two factors, namely group size and social pressure. His idea is that the benefits of lobbying dilute with an increasing number of group members. Hence, individual incentives to provide the public good are higher in small groups than in large groups. It is more likely that small groups are able to overcome the free-riding problem if group formation is to be expected at all. Moreover, social pressure may be a means of inhibiting free-riding. As it is more easily exerted in small groups, this aspect also tends to increase the likelihood that if interest groups emerge, then they are small.

Mitra (1999) abstracts from incentives to free-ride within interest groups. He extends the basic lobbying model and analyzes the entry decision of interest groups. These decisions determine the equilibrium number of interest groups and the degree of lobbying competition. Groups are heterogenous with respect to fixed costs of organization, and each group knows the entry costs of its opponents. Thus, lobbies are able to anticipate who enters in equilibrium, which allows them to derive the net benefit of its own entry decision and compare it to its costs.

The benefit of political participation consists of the utility gain from the induced policy change if the interest groups is active, net of necessary contribution payments to induce this change. The author shows that benefits decrease with lobbying competition. First, increased competition affects the structure of protection. Positive protection for organized groups decreases, because opposing interests tend to cancel each other out; negative protection of unorganized sectors increases, because the benefit on behalf of the organized increases with many active lobbies. It can be shown that the first effect dominates the second, and active lobby groups gain from low lobbying competition. Second, the benefit of entry depends negatively on the necessary contribution payments. With many active groups, contribution payments tend to be high due to pure number counting. But necessary compensation payments per lobby decrease if lobbying competition is strong, as well as the compensation for the decline in aggregate welfare. The total effect on contributions is thus ambiguous. However, it can be shown that in sum the negative effects dominate the positive ones and the benefit of entry declines in the number of interest groups.

In equilibrium, the number of lobbies as well as who enters is uniformly de- 
termined, because each group is able to calculate how many groups enter and who stays out. Those lobbies who do not organize anticipate that the cost of organization exceeds its net benefits, whereas those who enter anticipate that the degree of lobbying competition is small enough such that the benefit of entry exceeds its costs.

The author extends the model and derives comparative static results. For instance, if more individuals gain from factor specific income, the degree of lobbying competition declines. Intuitively, if more individuals benefit from high factor income through positive protection, less individuals can be exploited through negative protection. The net benefit of being active declines and less interest groups organize. Moreover, if the concern for contribution payments increases, the number of lobbies increases. The politician caters more to active lobbies in this case, which increases incentives to organize. ${ }^{9}$ Finally, if the assumption of homogenous groups is relaxed, it can be shown that sectors benefit more form organization if they are small, face inelastic demand, and have large capital stocks.

Damania and Fredriksson (2000) focus on incentives to free-ride in a setup where two interest groups follow a common interest. Each group may either abstain from lobbying, lobby alone, or form a coalition with the other lobby. The authors state conditions such that free-riding on the other firm's lobbying activities, joint lobbying, or unilateral lobbying occurs in the state game. If the game is repeated infinitely, cooperation may result even if free-riding is the optimal behavior in the state game. Cooperation is implemented through trigger strategies, which lets each firm cooperate as long as the other one does. Cooperation is more likely if the short hand benefit of defection is small relative to the discounted future benefits of cooperation.

\section{Signalling models}

This section gives an alternative explanation of why politicians may respond to interest groups. The argument does not rely on the assumption that politicians are self-interested. Rather, benevolent politicians have an incentive to listen to interest groups when they are imperfectly informed and lobbies possess better information about the relevant policy. For instance, the politician might be unsure about the preferences of the electorate, or about the state of the world in which the policy takes effect. Lobbies may be better informed, either because they are "closer" to the preferences of their members, or they have specific expertise in certain policy fields. This is the information motive for lobbying. Lobbying gives politicians a chance to improve their decisions in this context.

However, interest groups are self interested and politicians cannot simply trust 
their speeches. They have to extract the informative part of the received messages, based on their available a priori information. Lobby groups, on the other hand, know the way politicians discount their messages. They adjust their strategies accordingly to appear trustworthy. Formally, the relationship between interest groups and the politician is modelled as a signalling game in which these groups try to persuade a benevolent policy maker on a certain policy, who in turn improves the informational basis of his decision. They all rely on the equilibrium concept of Sequential or Perfect Bayesian Equilibria and, depending on the specific model characteristics, specific refinements. ${ }^{10}$ The models can be categorized according to the following table.

\begin{tabular}{|c|c|c|}
\hline policy & discrete & continuous \\
\hline number of lobbies & one & many \\
\hline access to the politician & costless & costly \\
\hline lobby's information & perfect & imperfect \\
\hline message & can be verified & can not be verified \\
\hline signal & informative & uninformative \\
\hline signalling costs & sunk & productive \\
\hline
\end{tabular}

Table 1: Categorization of signalling models.

Section 4.1 explains the basic signalling model with one interest group which submits information strategically. Section 4.2 extends this model to several lobbies and allows for lobbying competition. The relevant approaches can also be reinterpreted as models of "mass movement", if we interpret each lobby as an individual which has to decide if to take a certain action or not. For instance, this action may be the decision to participate in public demonstrations, or it may consist of individual activities like sending postcards, writing letters etc. Section 4.3 finally discusses various extensions to these models.

\subsection{The basic signalling model}

The models of Potters and van Winden (1992), and Ainsworth (1993) and Sloof (1997b) are basic signalling models whose intuition is broadly valid. There are two states of the world, denoted by $\theta_{1}$ and $\theta_{2}$, whose realization is not known to the politician, but known to the lobby. The politician has prior beliefs about the probability that a certain state occurs. Further, he implements one of the policy alternatives $\tau_{1}$ or $\tau_{2}$. Each alternative "fits" one state. The payoff to the politician is high if he implements the correct policy in each state and low if he implements the wrong one. Hence, the task of the politician is to choose 
a correct policy under uncertainty.

A single lobby guides the politician in his choice. This lobby observes the realized state of the world and has perfect information. It can inform the politician about the realized state by sending a costly signal. The cost of the signal is denoted by $c$. The politician, who observes only the signal but not the true state of the world, anticipates that sending a signal is only worth for certain types of interest groups. He updates his beliefs accordingly. The payoff to the lobby depends on the realized state of the world and may conflict with the interests of the politician.

The payoff matrix of the game and the ex ante probabilities are common knowledge. The first entry denotes the payoff to the politician. The second denotes the payoff to the lobby:

\begin{tabular}{|c|c|c|}
\hline & $\theta_{1}$ & $\theta_{2}$ \\
\hline$\tau_{1}$ & $a, 0$ & 0,0 \\
\hline$\tau_{2}$ & $0, d$ & $a, e$ \\
\hline
\end{tabular}

The payoff to the politician is always positive, that is $a>0$. The payoffs to the lobby are arbitrary and will be discussed in the following.

Suppose first that $d<0<e$. In this case, there is no conflict of interest between the politician and the lobby. They share the same interest, which is to find the policy suitable for each state of the world. There may or may not be an incentive for the lobby to send a message. This depends on the lobbying costs and on the politician's ex ante beliefs. What is of importance for this parameter range is that the politician can always trust the signal if he receives one. Thus in this situation, the policy maker is perfectly informed at the time he must implement the policy, since he knows that the lobby has no incentive to mislead him. Without a signal, he knows that the lobby has no incentive to send one, which indicates that the choice based on his a priori belief is the correct one.

Suppose next that $d>0>e$. This is the case of full conflict of interest, because the politician knows that he is better off mistrusting any signal he receives. Since he knows that, he will always ignore any signal. The lobby, anticipating the ignorance of the politician, knows that whatever it does, it has no effect. Hence it will never send a signal, because this is costly. In this setup, there is no scope for information transmission, since the interest of the two players are fully opposed.

The relevant parameter range in which signalling is a matter of interest is $d, e>$ 0 . This is the case of partial conflict between the lobby and the politician. All models correspond to this setup unless stated otherwise. It depends on the 
state of the world whether the two players have the same interest. Note that the lobby always prefers policy $\tau_{2}$, independent of the realized state of the world. If the state is $\theta_{2}$, the politician and the lobby follow a common interest. In the following, I shall denote the lobby in this particular state of the world as the "good type" and the corresponding state as the "good state". In contrast, if $\theta_{1}$ is relevant, the politician prefers $\tau_{1}$ and the lobby prefers $\tau_{2}$, and scope for conflict arises. The lobby and the state will be denoted as "bad type" and "bad state" respectively. In contrast to the full conflict of interest case, the politician will not systematically ignore any message, because he knows well that in some cases truth-telling is the preferred strategy of the lobby. Hence he can learn something from the signal he receives.

First, in order to make information revelation through signalling possible, we need to assume that the payoff to the bad type is smaller then the payoff to the good type, $d<e$. This condition is commonly known as the "sorting condition". It assures that the bad type can not always mimic the good type. Suppose the sorting condition does not hold: Then the payoff to the bad type is always weakly higher than the payoff to the good type. To achieve this, the bad type must only mimic the behavior of the good type (which he can always do if $d>e$ ). The politician anticipates this and should thus mistrust any signal. Information revelation is not possible in this case. But if the sorting condition is satisfied, mimicry is not possible in any state of the world. The good type has an incentive to send a signal in some states of the world, which the bad type does not have.

Second, note that the content of the signal is meaningless in this setup. The only informational content of the signal is the cost it induces. The intuition is as follows: If the message can be chosen arbitrarily, for instance "the state is $\theta_{1}$ " or "the state is $\theta_{2}$ ", the politician is able to derive the optimal contents of the message if one is sent. This is due to the fact that the politician knows the decision problem of the lobby, and is able to infer its best message. Since he can do so, not the choice of contents is important, but only the decision to send a signal or not. Hence all that matters are the signalling costs, but not the contents of the signal itself.

\section{Equilibria}

High signalling costs: The resulting equilibria depend on the signalling costs $c$, and on the politician's ex ante belief. If signalling costs are high $(c>e)$, a unique pooling equilibrium exists in which lobbies never send a signal, and the policy maker makes a choice based on his ex ante beliefs. ${ }^{11}$

Intermediate signalling costs: In contrast, if lobbying costs are intermediate $(d<c<e)$, then two types of equilibria exist, depending on the ex ante belief of the politician. Note first that the bad type will never send a message, 
since this induces a negative payoff even if it persuades the politician. So the focus is on the good type and its incentive to send a signal, which in turn depends on the ex ante belief of the politician concerning $\tau_{2}$. If the politician chooses the bad policy based on his a priori belief, the unique equilibrium is separating, and the good type always lobbies. Since the politician anticipates this, he trusts the signal and chooses policy $\tau_{2}$ after receiving a message, and the alternative policy otherwise. The good type has no incentive to deviate, because not sending a signal induces the unfavorable policy and zero payoff.

However, if the ex ante belief of the politician induces the good policy without signalling, two equilibria exist. The first and most obvious equilibrium is a pooling one, in which no signal is sent. If the politician anticipates this, he chooses the policy based on his prior beliefs which is the appropriate one. Moreover, there is also a separating equilibrium: If the politician assumes that the good type always indicates that $\theta_{2}$ is relevant, he only selects the good policy if this is affirmed. In this case, signalling is optimal only for the good type. Note that both equilibria induce different expected payoffs and welfare implications, which will be discussed below.

Low signalling costs: If signalling costs are low $(c<d)$, the bad lobby may try to mislead the politician. But it must consider the fact that the politician knows its incentive to do so. Hence the lobby needs to provide an incentive for the politician to listen to the signal. This incentive is not given if the bad type always signals, because the politician would anticipate this strategy and did not react. Thus signalling by the bad type is only a good strategy if it leaves a chance to extract some information from the signal. This is the case if the probability of a signal being sent by the good type is higher than the respective probability for the bad type.

If the politician's ex ante belief of the politician favors the bad policy, the good type has an incentive to always send a signal. Otherwise the bad type could mimic the good one. A unique semi-pooling equilibrium exists in which the good type always sends a signal, and the bad type plays a mixed strategy and mimics the good type every now and then. In this case, the politician is able to extract some (but not all) information from the signal. After having observed a signal, it is not optimal to choose the good policy in any case, because this also gives the bad type an incentive to send a signal in any case. Hence in equilibrium, the policy maker will sometimes choose the good policy if a signal is received, and otherwise not. Accordingly, the bad type will send a message now and then.

Next, consider the case where the politician chooses the good policy if he has to decide based on his a priori belief. In this case, no separating equilibrium exists, since a separating equilibrium requires that the good type always sends 
a message, whereas the bad type never does. But as argued above, this is no good strategy for the bad type if signalling costs are sufficiently low. Thus, only pooling and semi-pooling equilibria exist. There are two pooling equilibria. In the first, both types never lobby and the politician always chooses the good policy. No lobby has an incentive to send a costly signal, and the politician chooses the best policy based on his a priori beliefs. In the second pooling equilibrium, both types always lobby and the politician chooses the good policy only if he receives a signal. Note that not sending a signal cannot be optimal, because this would induce policy $\tau_{1}$, which yields a strictly lower payoff for the lobby. In the semi-separating equilibrium, the bad type never sends a message and the good type sends one every now and then. The politician anticipates these signalling strategies. He knows that a signal is a sure indicator of a good state of the world, but that the state of the world is not necessarily bad if no signal is sent. Accordingly, he chooses the good policy if he observes a signal; if he does not observe one, he occasionally chooses the good policy, because he knows that the good type sometimes remains silent.

\section{Welfare implications}

How can welfare effects be measured? Since the politician is benevolent, welfare is maximized if he implements the policy which maximizes his payoff. Note that welfare can be measured in one of two ways, either by the (ex ante) probability that the politician chooses the correct policy, or by observing whether the correct policy is implemented ex post. As a benchmark, consider the case without lobbying. In this case, the politician chooses the policy according to his a priori beliefs and maximizes expected welfare. Note that this does not imply that the correct policy is indeed implemented when the actual state of the world becomes known. The probability of an error depends on the a priori knowledge and the payoff of both policy choices. Does lobbying reduce the probability of an error? I focus on the effect of lobbying on welfare and abstract from lobbying costs in the following.

In separating equilibria, full information is revealed through lobbying. In this case, welfare is maximized and no error occurs. This makes the politician (and welfare net of lobbying costs) strictly better off compared to the case when no lobbying is allowed. There is only one separating equilibrium, namely when lobbying costs are intermediate. Observe that the lobby is not necessarily happy about its ability to lobby ex post: If the politician chooses the good policy based on his a priori belief, then the possibility to lobby decreases the payoff to both the good and the bad type: The good type lobbies and incurs costs in order to induce the good policy. But the politician would choose the good policy anyhow if the decision were solely based on his a priori knowledge and he knew that no lobbying is allowed. The bad type never realizes the positive payoff with lobbying (which on average it sometimes could without 
lobbying, depending on the a priori beliefs of the politician). Thus the good type is trapped into obligatory signalling and the bad type loses payoff. Hence the lobby would, ex ante and ex post, strictly prefer a regime without lobbying. This is not necessarily the case if the politician chooses the bad policy based on his a priori belief. In this case, the good type gets the chance to induce the good policy, and the bad type neither gains nor looses. Thus the expected benefit is strictly higher and the realized benefit is weakly higher when lobbying is allowed.

In contrast to the separating equilibrium, the politician does not gain any additional information if the types pool. Pooling equilibria only exist if the politician's ex ante belief favors the good policy. In this case, the politician's payoff and welfare are left unchanged if lobbying is possible. If the pooling equilibrium induces no lobbying by any type, then the no lobbying outcome is completely replicated and the expected payoff to the lobby does not change. If the pooling equilibrium induces lobbying of both types, then both types of lobbies are strictly worse off with lobbying and the expected payoff to the lobbies decrease. Note that pooling equilibria exist for low and intermediate signalling costs if the politician prefers the good policy based on his ex ante beliefs, and in general with high signalling costs.

Semi-separating equilibria occur only if lobbying costs are low. In these equilibria information is revealed, but the politician still retains a degree of uncertainty about the realized state. Moreover, the politician is sometimes mislead by the bad type. It turns out that the benefit of better information and the cost of sometimes being mislead cancel out. Hence the politician receives the same expected payoff as in the case without lobbying, and expected welfare remains unchanged. The payoff to the lobby depends on the politician's ex ante belief and the equilibrium strategies. If the politician chooses the bad state, both types benefit in expectation. Hence the lobby benefits in expectation even before it knows its type. This does not necessarily imply that it benefits ex post: Since the politician will sometimes choose policy $\tau_{1}$ despite signalling, the good type sometimes invests in lobbying without benefit. If the politician chooses the good policy based on his a priori beliefs, the good and the bad types lose in expectation, although the payoff to the bad type may ex post equal the payoff without lobbying. The good type looses for two reasons: The politician chooses the good policy less often and the lobby sometimes has to bear signalling costs. Thus the lobby's expected benefit decreases.

In short, lobbying tends to increase welfare if we abstract from lobbying costs. The politician learns the true state of the world in separating equilibria with certainty, and increases his knowledge if semi-separating equilibria emerge. Only if the types pool, do welfare effects tend to be negative. In this case, lobbies engage in costly activities without any effect on the politician's decision. 


\section{Comparative statics}

General comparative static results are difficult to obtain when multiple equilibria exist because a slight change in any variable may lead to a jump from one equilibrium to another. For this reason, only one general result is stated here. $^{12}$

The likelihood that lobbying occurs tends to increase in the payoffs to the lobbies and decrease in the signalling costs. This result seems plausible at first glance and is valid in most cases. The reason is that the lobbies have to weigh the expected benefit against the costs of lobbying. However, this relationship may be less clear cut in certain circumstances. In the assessment of their lobbying strategies, the lobbies must take account of the politician's reaction. If for instance the benefit of the bad type increases, the politician anticipates its higher incentive to lobby. This in turn makes him less willing to react to lobbying, which again decreases the lobbying incentives of the bad type. The general likelihood of lobbying depends on the magnitude of these effects, but tends to increase in payoffs.

\subsection{Lobbying competition and models of mass move- ment}

\section{Counteractive Lobbying}

Two approaches induce lobbying competition into the analysis. Austen-Smith and Wright (1992) focus on the aspect of counteractive lobbying of two lobbies with opposing interests. The politician decides between two policy alternatives. Based on his a priori belief, he chooses the policy of the benefitted group. This gives the opposing group incentives to induce a policy deviation through signalling, which in turn may lead to counteractive lobbying of the benefitted group, aimed at preventing any policy deviation. Hence lobbying of the benefitted group occurs only as counteractive lobbying, but never solely to backup the belief the politician. The occurrence of lobbying depends on the extent of verification costs for the politician and the cost of information acquisition for the lobbies.

Suppose that verification costs are small relative to investigation costs. The opposing group has an incentive to acquire costly information and send a signal in this case. The politician occasionally verifies the message and learns the truth. If he does not verify, he listens to the opposing lobby and modifies his policy decision accordingly. The benefitted group does not lobby in this case, because the cost of acquiring information is excessive compared to the chance of not loosing support occasionally, and counteractive lobbying does not occur in this case. In contrast if verification costs are high, the politician 
will not verify a single incoming signal and always verify if he receives two contrasting ones. This implies that he always listens to the opposing group if he does not also receive a second signal. Hence the benefitted group must engage in counteractive lobbying in order to prevent a loss of support. In this situation, both interest groups are trapped in ineffective lobbying, because the politician verifies the messages and learns the truth after signalling occurred.

\section{Models of mass movements}

The analysis of Lohmann (1993) (compare also Lohmann (1994) and Lohmann (1995b)) deviates from the basic lobbying model and yields some interesting new insights concerning lobbies' incentives to free-ride, and the effect of preference dispersion on the formation of mass movements. Again, the policy maker decides between two given policy alternatives, which are now elements of a continuous policy interval. There is a finite number of lobby groups, which are distributed along this interval. They are characterized by single peaked preferences about the policy in question, and each group prefers the policy alternative which is closer to its ideal point. The distribution of the groups along the interval is known to the politician. He is benevolent and seeks to maximize welfare through implementation of the median policy.

The median voter setup is modified in the following way: Each lobby (and the politician) knows that the effect of the policy does not only depend on the known part of the utility function, but also on the realized state of the world. The realized state is unobservable to the groups and the politician. It is drawn from the unit interval. Its distribution is common knowledge. Each group (but not the policy maker) receives an imperfect signal about the state of the world and updates its belief about its preferences accordingly. The signal serves as a "shifting" parameter which affects each group's assessment of the preferred policy. Then each decides to send a costly signal to the politician, which is interpreted (without loss of generality) as a vote for policy alternative $\tau_{1}$. The politician observes the number of signals, updates his belief concerning the preferred policy of the median voter, and decides accordingly.

Let me first provide some intuition for the lobbying decision of the interest groups. Each group compares the lobbying costs with the expected benefit, which depends on the utility difference between the policy alternatives, weighted by the probability that the lobbying effort is pivotal for the politician's choice. Consider first "extremists", who are defined as groups which prefer a policy alternative independent of the received signal. Extremists preferring $\tau_{1}$ always have an incentive to lobby, whereas extremists preferring the policy alternative will never do. Hence lobbying by extremists conveys no information if the politician knows that it is lobbied by extremists. In contrast, the preferred policy of "moderates" critically depends on the received signal. 
Those who receive a signal in favor of $\tau_{1}$ face incentives to lobby, whereas the others do not. Hence only lobbying by moderates conveys information to the politician, because their decision to lobby reveals information about the received signal. But not each groups facing incentives to lobby in fact do so, because incentives to free-ride exist. Net of lobbying costs, only some moderates facing incentives find it worthwhile to incur the costs. Hence, some moderates send a message while some free ride on others, even though both face incentives gross of lobbying costs.

Next consider the choice of the politician and the amount of extracted information. The politician is able to calculate the number of lobbying and abstaining extremists. Moreover, he is able to infer how many moderates will lobby given any possible realization of the state of the world. The difference between the observed number of lobbyists and the calculated number of extremists bears information about the state of the world. This is the information he is able to extract after observation of the lobbying movement. He updates his beliefs accordingly and then makes his policy choice. As interest groups anticipate this behavior in equilibrium, some do in fact engage in costly lobbying.

The critical parameters which determine the amount of information revelation are the lobbying costs and the dispersion of preferences across all individuals. Consider the case of almost homogenous individuals and no lobbying costs, such that all individuals are moderates. By counting the number of lobbyists, the politician is able to infer how many received a signal in favor of policy $\tau_{1}$. He is able to extract all information which is dispersed across the population in this case. (This is not equivalent to full information, because the aggregate dispersed information is itself a signal about the true state of the world.) In contrast, full information revelation is not possible if preferences are heterogenous. Some lobbyists are extremists, and number counting of extremists delivers no information. As extremists are more likely to occur if preferences are dispersed, less information is revealed in equilibrium if the population is less homogenous. Second, lobbying costs increase moderates' incentives to free-ride. More moderates abstain, which decreases the amount of information to the politician.

In sum, lobbying is more likely to increase welfare if the population is homogenous and lobbying costs are small: Positive lobbying costs reduce the amount of revealed information because more free-riders abstain from lobbying; heterogenous preferences reduce information revelation because more lobbying is done by extremists, which is uninformative. Note that there is some kind of "policy neutrality" of lobbying activities. Exogenous asymmetries between lobby groups have no effect on the induced policy change through political action. The politician knows how many individuals have an incentive to lobby and discounts the observed number accordingly. Being large is not worth much 
if the politician expects a large movement; and being few may be effective if the politician expects no engagement based on his a priori beliefs.

\subsection{Extensions}

\subsubsection{Information acquisition}

\section{By the politician}

Suppose that the policy maker has the opportunity to learn the true state of the world either by independent investigation if no lobbying occurs or verification of a received signal (Rasmusen 1993). (Compare also Rasmusen (1997) and Sloof (1997c). For a variation of the following theme, Potters and van Winden (1992), Austen-Smith and Wright (1992), and Sloof (1997a).) Investigation and verification are costly, with investigation exceeding verification costs. The analysis focusses on the semi-separating equilibrium which results if lobbying costs are small and the politician selects the unfavorable policy based on his a priori beliefs.

the resulting equilibria depend on the relation between investigation and verification costs. Obviously, if verification costs are high, verification is no option and the equilibrium does not change compared to the basic model. Suppose that verification costs are low, but investigation costs are prohibitively high such that the politician never investigates. The interest group still has incentives to signal despite the risk of verification. In equilibrium, the good type always lobbies, the bad type lobbies sometimes and the politician verifies now and then. Lobbying of the bad type is successful if it is not verified, which induces a policy change. Expected gross welfare increases compared to the basic model in this case. The bad type has less incentives to mislead the politician, because it faces the risk of exposure through verification. It lies less often, which improves the politician's decision and decreases its expected payoff. Note that this equilibrium also holds if investigation costs are low, but there are additional equilibria in this case. One is a pooling equilibrium without lobbying, and investigation by the politician. This equilibrium is characterized by the fact that the good type passes on signalling costs to the politician, since the good policy is always implemented without any need to lobby.

\section{By the lobby}

Lagerlof (1997) extends the basic model and assumes that the interest group is imperfectly informed. Investigation by the lobby implies that it learns the true state of the world with an exogenously given probability. The politician cannot observe if the lobby investigates. In the second stage, the interest 
groups decides whether it sends a signal or not. Lying is not possible. The insight of this paper is that the lobby may be forced to acquire information if the politician expects it to do so, even though it would not do so if the politician did not update his beliefs to its disadvantage in case of no lobbying. Hence the lobby may be trapped in information acquisition which reduces its expected payoff, but increases expected aggregate welfare.

\subsubsection{Endogenous signalling costs: Access buying}

Signalling costs are exogenous in the previous models. But they contain information about a lobby's value of being heard if the lobby or the politician are able to determine these costs endogenously. Signalling costs serve as an access device in this case, which inform the politician about the benefit of grating access to certain groups.

Lohmann (1995a) uses a slightly modified setup of her model of mass movement to focus on contributions as an access device (compare also Austen-Smith (1995) and Austen-Smith (1998)). In this modification, each lobby either sends one of two costless messages, indicating which policy alternative it prefers, or no message at all. Lying is possible. To convince the politician that it is worth to consider the signal as being informative, each group offers an individual amount of contributions. These serve as an access device, indicating if a lobby has something to say. They do not increase the payoff to the politician.

Two key insights result from this modification: First, moderates gain access without costs, because the politician anticipates that moderates have no incentives to lie. Their messages are influential with zero contributions. In contrast, extremists may have incentives to lie if they receive a signal which contradicts its prior preferences. Those receiving backing signals have incentives to report this truthfully. Hence the politician and truth-telling interest groups prefer to separate truth-tellers from liars. Contributions are a means for that: Since both types of extremists update their beliefs about the expected gain from either policy, extremists who receive an encouraging signal and update their beliefs accordingly have a higher stake in the preferred policy than extremists who receive an unfavorable signal. Full separation between these groups is possible: The politician listens only to those messages which are accompanied by contributions worth to be paid for "those who have something to say". Second, full information is revealed in equilibrium, because all moderates send messages (free-riding does not occur because access costs are zero for moderates). Moreover, extremists separate completely through the offer of contribution payments. 


\subsubsection{Signalling as instrument with two purposes}

Some studies conceptualize contribution payments and informational lobbying in a single framework. The idea is that a single lobbying instrument embodies both channels of influence, namely information transmission and buying goodwill. Depending on the relevant setup, either the politician sets an access charge which reflects his interest in information and money (Austen-Smith 1998), or the lobby offers a contribution schedule which buys goodwill and reveals information about the lobby's type (Ball 1995). (Compare Prat (2001), Mueller and Stratmann (1994) for models in the context of electoral competition.) Both models differ with respect to their particular setup, but the resulting equilibria reflect a general insight: Contributions deteriorate policies, because a self-interested politician has incentives to sacrifice aggregate welfare for money. However, contributions also serve as a signalling device and entail helpful information for the politician. The equilibria reflect this trade-off: Lobbying tends to increase welfare for informational reasons, but not as much as if the politician was completely benevolent and did not care for contribution payments.

\subsubsection{Miscellaneous}

Some analysis of signalling do not fit well into one of the above categorizations. For instance, Sloof and van Winden (2000) analyze a lobby which can build up reputation through two different types of lobbying activities. They show that a lobby may have incentives to "show their teeth first" in order to build up reputation, even if this decreases profits in the short run. Bennedsen and Feldman (2000) compare different institutions in a signalling setup and analyze lobbies' incentives to engage in political action. Finally, Ainsworth and Sened (1993) analyze lobbying incentives of an interest group which acts as an intermediary between the politician and the population, and behaves strategically vis a vis both.

\section{The instrument choice of lobbies}

The literature on lobbying divides into two broad strands as the preceding sections indicate: Lobbying is analyzed either as contribution payments, or as a means of transmitting information. The question arises which type of lobbying interest groups prefer. To my best knowledge, there are only two recent approaches which pick this question as a central theme. I will indicate the first steps of this promising direction of research in the following. 
Bennedsen and Feldmann (2002) focus on the instrument choice of lobbying. They assume that an interest group may influence a political decision in two independent ways: First, it may engage in costly information acquisition and transfer the result truthfully, as is known form the signalling literature. Second, the lobby determines contribution payments, which compensates the politician for a deviation towards its preferred policy choice. The question arises which type of lobbying the interest group prefers, and how these instruments affect each other.

The approach resembles some insights from the signalling literature: Abstracting from contributions payments, the interest group is c.p. more likely to engage in informational lobbying if the cost of information acquisition is small, the stakes in the preferred policy are large, and the probability of successful investigation is high. And given that the politician has a belief about the state of the world, the lobby exactly compensates the politician in order to achieve a certain policy deviation.

The authors then focus on the interaction between both types of lobbying. Consider the decision to acquire costly information. The politician updates his belief to the benefit of the lobby if he receives a signal, but to its disadvantage if he receives none. The latter case implies that investigation entails indirect search costs, because the politician updates his beliefs to the disadvantage of the lobby in case of negative search results. Hence, the decision to invest in information acquisition may on the one hand render contribution payments unnecessary, but on the other hand increase necessary contribution payments in the case of bad news. The authors show that the indirect search costs increase if the lobby has high stakes in the preferred policy outcome, or the probability of successful information acquisition is small. Hence the existence of contribution payments as an alternative lobbying instrument makes informational lobbying less likely. ${ }^{13}$ Note that both types of lobbying may occur if informational lobbying is beneficial in expectation, but turns out to be unsuccessful ex post.

Polk and Schmutzler (2002) focusses on lobbying competition and the instrument choice in a reduced form approach. Two interest groups engage in lobbying against environmental regulation. Two types of lobbying exist, which both increase individual pollution standards: General lobbying leads to higher pollution standards for all interest groups, which implies that lobbies provide a public good with respect to each other through this type of lobbying. For instance, general lobbying efforts may be informational lobbying which informs the politician about the consequences of environmental regulation. Additionally, both lobbies may also engage in private lobbying. They compete through this type of engagement, because private lobbying increases the individual pollution on account of the opponent. For instance, private lobbying may induce 
loopholes to one group, which restricts the availability of loopholes to the other group.

The question arises in which lobbying type the interest groups engage and which policy emerges. Suppose that the politician becomes more responsive to private lobbying. As a direct effect, the increase of the marginal benefit of private lobbying leads to more private and less general lobbying. But private lobbying efforts are strategic substitutes, which might dampen or counteract the first effect. It turns out that both interest groups increase private lobbying in a symmetric equilibrium, but that both may react differently in an asymmetric setup.

The main insight is that the politician may actively increase lobbying competition between interest groups by getting more responsive to private lobbying. This induces diversion from general to private lobbying. He may have incentives to do so, as the political decision and the environmental quality tend to improve: ${ }^{14}$ Counteractive activities dominate in this case and lobbies are trapped in ineffective distributional activities. Instead of jointly lobbying against environmental regulation, they divert from their original interest. Hence, the model indicates that a politician's ability to react to a certain type of lobbying may affect the lobbying instruments employed by interest groups.

Despite these two approaches, open questions for further research remain. For instance, what determines which type of lobbying occurs? Does this depend on the policy at stance, the degree of lobbying competition, or public concern about the policy? The general task is to combine these two independent approaches towards lobbying, at which end of line a general lobbying model may possibly emerge.

\section{Conclusions}

This survey deals with two main channels of how interest groups influence political decisions. The common agency approach views politics as a market, where contribution payments buy policies. Payments may be legal donations or illegal bribes, but the underlying idea is of much broader scope and lies beyond pure money offers. For instance, contributions may take on the form of job promises past the incumbency, campaign sponsorship, or backing from specific groups like trade-union members or addicts of the tabloid press. The main assumption of this approach is that politicians follow individual objectives which depart from maximization of aggregate welfare.

The second channel of influence abstracts from the idea that politicians are self-interested. It relies on the concept of asymmetric information. The idea 
is that politicians face capacity constraints, which give them informational disadvantages vis a vis lobbies. Time constraints of politicians are not the only reasons why this is the case. Political decisions are often very important for specific sectors, which provides the relevant interest groups with strong incentives to concentrate forces. In contrast, politicians have to spread their forces on a diverse range of politics at the same time. Moreover, companies often possess private information which is important for the political decisions, as for instance data about costs and demand, or technological expertise.

The above examples lead to the impression that welfare effects of lobbying are negative. From a theoretical point of view, this is indeed true if lobbying takes the form of contribution payments in exchange for political favors. As indicated in sections 2 and 3, aggregate welfare declines if politicians deviate from first best practices, which incurs deadweight losses on behalf of the public. A prohibition of lobbying improves aggregate welfare according to this approach. The extent of the negative lobbying effect depends on specific circumstances. For instance, if lobbying competition and conflict of interest is strong, the expected decline of aggregate welfare is relatively small. Thus, a prohibition of lobbying in policy fields with a large set of strong and opposing interest groups will not improve welfare much. It only serves to reduce lobbying expenditures. Moreover, the effect of a prohibition depends on the extent of the politician's weight on aggregate welfare if lobbying influence is intense. If we expect that politicians care about aggregate welfare in policy areas attracting much public attention (and they care less about aggregate welfare in apparently unimportant fields), lobbying is influential in unpopular policy fields. Hence, negative welfare effects occur especially in areas which are important but arise little public attention. In contrast, lobbying in policy fields with much public attention is less effective, especially if competing interests are active.

In contrast to this view, lobbying may well be welfare-enhancing if it improves the informational basis of political decisions. Particularities depend on signalling costs, the degree of lobbying competition, and the extent of politicians' information if no lobbying takes place. For instance, if signalling costs are high enough separation between those who truthfully inform the politician about the state of the world and others results. Aggregate welfare (net of lobbying costs) increases. If information is good even without lobbying, the politician will extract only little new information. In this case lobbying has only minor positive welfare effects; it may even turn negative if we take account of its costs and of the idea that lobbying efforts are probably unproductive activities (Bhagwati 1995). Lobbying competition has ambiguous effects: On the one hand, it tends to improve information available to the politician. On the other hand, more uninformative money is spent in the lobbying process (compare section 4.2). 
The distribution of gains from lobbying depends on different factors. First, it is a relatively robust insight that politicians improve their payoffs through lobbying. Lobbying provides benefits either in the form of contribution payments or through transmission of information. This result is not surprising: If politicians do not benefit from lobbying, foreclosure is an option. Hence they can always do at least as good with lobbying as without. Accordingly, their payoff must increase if they allow lobbying activities.

The effect of lobbying on unorganized interests depends on the channel of influence. Consider contribution payments: In this case, politicians deviate from welfare maximizing policies in order to attract money. Unorganized interests lose. They are the victims of policies motivated by selfishness, which impose costs on the public. The best possible (and rather theoretical) situation is that lobbying exposes no costs on the unorganized. This is the knife edge case of strong lobbying competition, where lobbies engage in pure counteractive activities and no welfare effect occurs. On the other hand, it is a relatively robust insight that unorganized interests benefit from lobbying if it takes the form of information transmission. Although lobbies are now and then able to mislead the politician to the disadvantage of the public, in aggregate the quality of political decisions improves. The intuition is that politicians extract information, which is not available if no lobbying takes place.

Payoffs of organized interests depend on the degree of lobbying competition. Benefits tend to decrease if lobbying competition is strong. For instance, a single lobby is able to extract the full private rent created through political interaction, and it benefits from the possibility of lobbying. In contrast, lobbies are captured in inefficient activities if lobbying competition is strong. In this case, interests groups loose. They have incentives to cooperate or even prefer a prohibition of lobbying. These insights are broadly valid for both types of influence channels, even though subtleties remain. For instance, the extent of the benefits to lobbies depend on the degree of policy efficiency. With weak lobbying competition, efficient policy instruments tend to increase lobbies' payoffs. Compensations for policy deviations need to be rather small in this case. But the reverse holds if lobbying competition is strong (compare section 3.2). Compensation payments need to be high in order to prevent the politician from an unfavorable policy deviation if the policy instrument is efficient. As a second example, consider the free-riding aspect of lobbying. It occurs if several lobbies follow a common interest. In this case, lobbying benefits are high because competition is weak. But benefits depend also on the possibility of free-riding. If free-riding is easy, less than optimal influence occurs from a lobbies' point of view, which tends to decrease payoffs. Lobbies with small policy stakes tend to gain from free-riding, whereas those with high stakes loose. 
This leads us to the insight that relevant policy fields for effective lobbying are characterized by weak lobbying competition, rather symmetric interests, little public attention and efficient policy instruments for redistribution. Moreover, much can be gained if information transmission is important for the politician. It is noteworthy that politicians always gain from lobbying, whereas lobbies do not necessarily do so. Politicians benefit more if lobbying competition is high, the policy instrument is efficient and little public attention arises. Politicians are the winners of this game, special interests only sometimes. Accordingly, it is not surprising that politicians have only small incentives to prohibit lobbying - except possibly in a few policy fields arising much public attention.

There is ample scope for further research. As already indicated, the instrument choice of lobbies is not yet well understood: In which type of lobbying activities do interest groups engage? And what are the relevant determinants of this choice? Moreover, the question of group formation yields room for further research. For instance, why do we observe many influential large interest groups in reality, although theory predicts that small groups can easier overcome the free-rider problem? Fixed costs of group formation may be an answer to this question, but this should be made more precise and enriched by further arguments. Finally, empirical insights are still rare in this important field of research, especially in the context of European politics. Case studies may help to gain insights where a lack of data prohibits empirical research. 


\section{Notes}

${ }^{1}$ Models of electoral competition (Baron 1989, Besley and Coate 2001) as well as models focusing on institutional setups (Bennedsen and Feldman 2000) are not subject of this survey. For a recent survey on empirical investigations, consider for instance Sloof (1997b).

${ }^{2}$ Compare Helpman (1995), Rodrik (1995), Austen-Smith (1996), Sloof (1997b), Persson (1998), Persson and Tabellini (2000), Potters and van Winden (1996), Ursprung (2000).

${ }^{3}$ To be precise, note that the model does not incorporate cooperative behavior, which is necessary to form such a coalition. Rather, think of the 'joint deviation' as a deviation which is induced by the lobby through an appropriate modification of the contribution function.

${ }^{4}$ Note that there may be policy alternatives which reduce the utility level of the individual compared to the reference policy. The principal offers zero contributions for these alternatives, because contributions are restricted to be non-negative. His payoff for these policy alternatives is then smaller than the payoff of the reference policy.

${ }^{5}$ For empirical evidence consult Goldberg and Maggi (1999), and Gawande and Bandyopadhyay (2000).

${ }^{6}$ Analogous results hold for the exporting sectors.

${ }^{7}$ Domestic contribution offers are not observed by the foreign country. This implies that governments cannot set their trade policies dependent on the contribution offers of the foreign lobbies, which in turn implies that lobbies do not set their contribution offers to influence the foreign country. The definition of the equilibrium reflects this: Contribution offers and trade policies are best responses to the other country's trade policy, but not to foreign contribution offers.

${ }^{8}$ Note that the small country assumption of the basic lobbying model can be interpreted as infinite foreign supply and demand elasticities.

${ }^{9}$ Note that the effect on the equilibrium structure of protection is ambiguous in this case, and positive protection of the organized may increase or decrease: If the politician caters more to interest groups, positive protection increases for a given number of interest groups. But more groups organize and lobbying competition increases, which tends to decrease protection. The total effect is ambiguous. Negative protection of the unorganized increases in any case, because more individuals gain from exploitation of the unorganized, and the politician caters more to special interests even with a given number of interest 
groups.

${ }^{10}$ Equilibria are characterized by strategies for each player and beliefs about the uncertain states of the world at the time a player is called upon to act. The equilibrium strategies are chosen such that each player's expected payoff is maximized, given the other players' equilibrium strategies and their beliefs about the states of the world. Beliefs are derived from the a priori knowledge and updated according to Bayes' rule. Compare for instance Gibbons (1992), Fudenberg and Tirole (1991), Mas-Colell, Whinston and Green (1995).

${ }^{11}$ The term "lobbies" refers to the different types of the lobby.

${ }^{12}$ For details consult Potters and van Winden (1992).

${ }^{13}$ Investigation is more likely if the politician is not able to observe whether the lobby investigates or not. The expected loss of a disadvantageous search is smaller in this case, because the politician is left with uncertainty over whether the absent signal is due to no search effort instead of bad news.

${ }^{14}$ The responsiveness towards private lobbying may also depend on the type of regulation under consideration. For instance, a certain type of regulation may be achieved through different policy alternatives, leaving more discretion to the politician. In this case, it is likely that interest groups engage in private lobbying, and general lobbying becomes relatively unimportant. On the other hand, if only a single policy instrument is available to achieve a certain policy outcome, policy discretion is small. It is likely that interest groups will focus on general lobbying in this case, which leads to effective lobbying and low regulation. 


\section{References}

Aidt, Toke S. (1997). Cooperative Lobbying and Endogenous Trade Policy. Public Choice, 93:455-475.

- (1998). Political Internalization of Economic Externalities and Environmental Policy. Journal of Public Economics, 69(1):1-16.

Ainsworth, Scott (1993). Regulating lobbyists and interest group influence. Journal of Politics, 55:41-56.

Ainsworth, Scott and Itai Sened (1993). The Role of Lobbyists: Entrepreneurs with Two Audiences. American Journal of Political Science, 37(3):834866.

Austen-Smith, David (1995). Campaign Contributions and Access. American Political Science Review, 89(3):566-581.

Austen-Smith, David, ed. (1996). Interest Groups: Money, information, and influence. Perspectives on Public Choice. Cambridge University Press.

Austen-Smith, David (1998). Allocating Access for Information and Contributions. Journal of Law, Economics, and Organization, 14(2):277-303.

Austen-Smith, David and John R. Wright (1992). Competitive Lobbying for a Legislator's Vote. Social Choice and Welfare, 9(3):229-257.

Ball, Richard (1995). Interest Groups, Influence and Welfare. Economics and Politics, 7(2):119-46.

Baron, David P. (1989). Service-Induced Campaign Contributions and the Electoral Equilibrium. Quarterly Journal of Economics, 104(1):45-72.

Becker, Gary S. (1983). A Theory of Competition among Pressure Groups for Political Influence. Quartely Journal of Economics, 143(3):371-400.

Bennedsen, Morten and Sven E. Feldman (2000). Lobbying Legislatures. Working Paper.

Bennedsen, Morton and Sven Feldmann (2002). Informational Lobbying and Political Contributions. Journal of Political Economics, forthcoming.

Bernheim, B. Douglas and Michael D. Whinston (1986a). Common agency. Econometrica, 54:923-942.

- (1986b). Menu Auctions, Resource Allocation, And Economic Influence. Quarterly Journal of Economics, 51(1):1-31. 
Besley, Timothy and Stephen Coate (2001). Lobbying and Welfare in a Representative Democracy. Review of Economic Studies, 68(1):67-82.

Bhagwati, Jagdish N. (1995). Directly Unproductive, Profit-Seeking (DUP) Activities. In ed Rogowski, Ronald, ed., Comparative politics and the international political economy. Volume 2. Elgar Reference Collection. Library of International Political Economy vol. 8, 1995, pages 83-97. Elgar; distributed in the U.S. by Ashgate, Aldershot, U.K.

Damania, R. and P. G. Fredriksson (2000). On The Formation Of Industry Lobby Groups. Journal of Economic Behavior and Organization, 41(4):315-336.

Damania, Richard (1999). Political competition, rent seeking and the choice of environmental policy instruments. Environmental and Resource Economics, 13(4):415-433.

Dixit, Avinash (1996). Special-Interest Lobbying and Endogenous Commodity Taxation. Eastern Economic Journal, 22(4):375-388.

Findlay, R. and S. Wellisz (1982). Endogenous Tariffs, the Political Economy of Trade Restrictions, and Welfare. In J. Bhagwati, ed., Import Competition and Response, 223-234. University Chicago Press.

Fudenberg, Drew and Jean Tirole (1991). Game Theory. MIT Press, Cambridge, MA London, England.

Gawande, Kishore and Usree Bandyopadhyay (2000). Is Protection for Sale? Evidence on the Grossman-Helpman Theory of Endogenous Protection. The Review of Economics And Statistics, 82(1):139-152.

Gibbons, Robert (1992). A Primer in Game Theory. Harvester Wheatsheaf, New York.

Goldberg, Pinelopi K. and Giovanni Maggi (1999). Protection for Sale: An Empirical Investigation. American Economic Review, 89(5):1135-1155.

Grossman, Gene M. and Elhanan Helpman (1994). Protection for Sale. American Economic Review, 84(4):833-850.

- (1995). Trade Wars and Trade Talks. Journal of Political Economy, 103(4):675-708.

Hahn, Robert W. (1990). The Political Economy of Environmental Regulation: Towards a Unifying Framework. Public Choice, 65(1):21-47. 
Helpman, Elhanan (1995). Politics and Trade Policy. NBER Working Paper 5309.

Hillman, Arye L. (1982). Declining Industries and Political-Support Protectionist Motives: Errata. American Economic Review, 72(5):1180-1187.

— (1989). The Political Economy of Protection. Harwood Academic Publishers, Chur, London and New York.

Johnson, Harry G. (1954). Optimum Tariffs and Retaliation. Review of Economic Studies, 21(2):142-153.

Lagerlof, Johan (1997). Lobbying, Information, and Private and Social Welfare. European Journal of Political Economy, 13(3):615-37.

Laussel, Didier and Michel Le Breton (2001). Conflict and Cooperation. Journal of Economic Theory, 100:93-128.

Levy, Philip I. (1999). Lobbying and International Cooperation in Tariff Setting. Journal of International Economics, 47:345-370.

Lohmann, Susanne (1993). A Signaling Model of Informative and Manipulative Political Action. American Political Science Review, 87(2):319-33.

- (1994). Information Aggregation through Costly Political Action. American Economic Review, 84(3):518-30.

- (1995a). Information, Access, and Contributions: A Signalling Model of Lobbying. Public Choice, 85:267-284.

- (1995b). A Signaling Model of Competitive Political Pressures. Economics and Politics, 7(3):181-206.

Long van, Ngo and N. Vousden (1991). Protectionist Responses and Declining Industries. Journal of International Economics, 30:87-103.

Maggi, Giovanni and Andres Rodriguez Clare (2000). Import Penetration and the Politics of Trade Protection. Journal of International Economics, 51(2):287-304.

Mas-Colell, Andreu, Michael D. Whinston and Jerry R. Green (1995). Microeconomic Theory. Oxford University Press, New York.

Mitra, Devashish (1999). Endogenous Lobby Formation and Endogenous Protection: A Long-Run Model of Trade Policy Determination. American Economic Review, 89(5):1116-1143. 
Mueller, Dennis C. and Thomas Stratmann (1994). Informative and Persuasive Campaigning. Public Choice, 81(1-2):55-77.

Neven, Damien and Lars-Hendrik Röller (2000). Consumer Surplus vs. Welfare Standard in a Political Economy Model of Merger Control. Discussion Paper FS IV 00-15, Wissenschaftszentrum Berlin.

Olson, Mancur (1965). The Logic of Collective Action: Public Goods and the Theory of Groups. Harvard University Press, Cambridge, Mass.

Pecorino, Paul (1997). Exogenous Tariff Changes with an Endogenous Lobby. Public Choice, 92:91-108.

Peltzman, Sam (1976). Toward A More General Theory of Regulation. Journal of Law and Economics, 19(2):211-240.

Persson, Torsten (1998). Economic Policy and Special Interest Politics. Economic Journal, 108(447):310-27.

Persson, Torsten and Guido Tabellini (2000). Political Economics. MIT Press, Cambridge, MA London, England.

Polk, Andreas and Armin Schmutzler (2002). Lobbying against environmental regulation vs. lobbying for loopholes. Working Paper of the Socioeconomic Institute. University of Zurich.

Potters, Jan and Frans van Winden (1992). Lobbying and asymmetric information. Public Choice, 74:269-292.

- (1996). Models of Interest Groups: Four Different Approaches. In Norman ed Schofield, ed., Collective decision making: Social choice and political economy. With the assistance of Annette Milford. Recent Economic Thought Series, 337-62. Kluwer Academic, Boston; Dordrecht and London.

Prat, Andrea (2001). Campaign Spending with Office-Seeking Politicians, Rational Voters, and Multiple Lobbies. Journal of Economic Theory, forthcoming.

Rama, Martin and Guido Tabellini (1998). Lobbying by capital and labor over trade and labor market policies. European Economic Review, 42:12951316 .

Rasmusen, Eric (1993). Lobbying when the decisionmaker can acquire independent information. Public Choice, 77:899-913. 
- (1997). Choosing among Signalling Equilibria in Lobbying Games: A Reply to Sloof. Public Choice, 91(2):209-14.

Rodrik, Dani (1995). Political Economy and Trade Policy. In Gene-M. Grossman and Kenneth Rogoff, eds., Handbook of international economics. Volume 3. Handbooks in Economics, vol. 3, 1457-1494. Elsevier, North Holland, Amsterdam, New York and Oxford.

Sloof, Randolph (1997a). Competitive Lobbying for a Legislator's Vote: A Comment. Social Choice and Welfare, 14(3):449-64.

- (1997b). Game-theoretic Models of the Political Influence of Interest Groups, volume 143 of Tinbergen Institute Research Series. Thesis Publishers Amsterdam, Amsterdam.

- (1997c). Lobbying When the Decisionmaker Can Acquire Independent Information: A Comment. Public Choice, 91(2):199-207.

Sloof, Randolph and Frans van Winden (2000). Show them your teeth first! Public Choice, 104:81-120.

Ursprung, Heinrich W. (2000). Die Modellierung endogener Handelspolitik: "The Rake's Progress". Aussenwirtschaft, 55(1):85-119.

Wellisz, Stanislaw and D. Wilson, John (1986). Lobbying and Tariff Formation: A Deadweight Loss Consideration. Journal of International Economics, 20:367-375. 
The Working Papers of the Socioeconomic Institute can be downloaded in from http:/www.soi.unizh.ch/research/wp/index2.html

$0206 \quad$ How Special Interests Shape Policy - A Survey

Andreas Polk, 2002, 41 p.

$0205 \quad$ Lobbying Activities of Multinational Firms

Andreas Polk, 2002, 32 p.

0204 Subjective Well-being and the Family

Rainer Winkelmann, 2002, 18 p.

$0203 \quad$ Work and health in Switzerland: Immigrants and Natives

Rainer Winkelmann, 2002, 27 p.

0202 Why do firms recruit internationally? Results from the IZA International Employer

Survey 2000

Rainer Winkelmann, 2002, 25 p.

0201 Multilateral Agreement On Investments (MAI) - A Critical Assessment From An

Industrial Economics Point Of View

Andreas Polk, 2002, 25 p.

0103 Finanzintermediäre Grössennachteile und Spezialisierungsvorteile

Michael Breuer, 2001, 31 p.

$0102 \quad$ How to Regulate Vertical Market Structure in Network Industries

Stefan Buehler, 2001, 35 p.

$0101 \quad$ Empirische Analyse des Zeitpunktes schweizerischer Direktinvestitionen in Osteuropa Markus König, 2001, 26 p.

$0003 \quad$ Measuring Willingness-To-Pay for Risk Reduction: An Application of Conjoint Analysis

Harry Telser, Peter Zweifel, 2000, 21 p.

$0002 \quad$ Quality Provision in Deregulated Industries: The Railtrack Problem

M.A. Benz, S. Bühler, A. Schmutzler, 2000, 32 p.

0001 Is Swiss Telecommunications a Natural Monopoly? An Evaluation of Empirical Evidence

Stefan Bühler, 2000, 23 p.

9906 Innovation and the Emergence of Market Dominance, Susan Athey and Armin Schmutzler, 1999, 42 p.

$9905 \quad$ Multilaterale Investitionsabkommen - Lernen aus dem MAl?

Andreas Polk, 1999, 32 p. 